CLINICAL STUDY

\title{
Thyroid hormone independent associations between serum TSH levels and indicators of bone turnover in cured patients with differentiated thyroid carcinoma
}

\author{
Karen A Heemstra*, Wendy M van der Deure ${ }^{1, *}$, Robin P Peeters ${ }^{1}$, Neveen A Hamdy, Marcel P Stokkel ${ }^{2}$, \\ Eleonora P Corssmit, Johannes A Romijn, Theo J Visser ${ }^{1}$ and Johannes W Smit \\ Department of Endocrinology and Metabolism, C4-R, Leiden University Medical Center, PO Box 9600, 2300 RC Leiden, The Netherlands, ${ }^{1}$ Department of \\ Internal Medicine, Erasmus University Medical Center, Rotterdam, The Netherlands and ${ }^{2}$ Department of Nuclear Medicine, Leiden University Medical \\ Center, Leiden, The Netherlands \\ (Correspondence should be addressed to J W A Smit; Email: jwasmit@lumc.nl)
}

*K A Heemstra and W M van der Deure contributed equally to this work

\begin{abstract}
Objective: It has been proposed that TSH has thyroid hormone-independent effects on bone mineral density (BMD) and bone metabolism. This concept is still controversial and has not been studied in human subjects in detail. We addressed this question by studying relationships between serum TSH concentration and indicators of bone turnover, after controlling for triiodothyronine $\left(\mathrm{T}_{3}\right)$, free thyroxine $\left(\mathrm{FT}_{4}\right)$, and non-thyroid factors relevant to $\mathrm{BMD}$ and bone metabolism. We also studied the contribution of the TSH receptor (TSHR)-Asp727Glu polymorphism to these relationships.

Design: We performed a cross-sectional study with 148 patients, who had been thyroidectomized for differentiated thyroid carcinoma.

Methods: We measured BMD of the femoral neck and lumbar spine. $\mathrm{FT}_{4}, \mathrm{~T}_{3}$, TSH, bone-specific alkaline phosphatase, procollagen type 1 aminoterminal propeptide levels, C-cross-linking terminal telopeptide of type I collagen, and urinary N-telopeptide of collagen cross-links were measured. Genotypes of the TSHR-Asp727Glu polymorphism were determined by Taqman assay.

Results: We found a significant, inverse correlation between serum TSH levels and indicators of bone turnover, which was independent of serum $\mathrm{FT}_{4}$ and $\mathrm{T}_{3}$ levels as well as other parameters influencing bone metabolism. We found that carriers of the TSHR-Asp727Glu polymorphism had an $8.1 \%$ higher femoral neck BMD, which was, however, no longer significant after adjusting for body mass index. Conclusion: We conclude that in this group of patients, serum TSH was related to indicators of bone remodeling independently of thyroid hormone levels. This may point to a functional role of the TSHR in bone in humans. Further research into this mechanism needs to be performed.
\end{abstract}

European Journal of Endocrinology 159 69-76

\section{Introduction}

The effects of thyroid hormone on bone metabolism are well established, ranging from decreased skeletal development in childhood hypothyroidism to an increased risk for osteoporosis in hyperthyroidism (1-3). The pathophysiology of osteoporosis in hyperthyroidism is multifactorial $(4,5)$, including shortening of the bone remodeling cycle (6) and acceleration of bone turnover (7). Thyroid hormone indirectly promotes osteoclast formation and activation by inducing the expression of cytokines, prostaglandins, and the receptor activator of nuclear factor NFKB ligand (RANKL) (8-10). Apart from overt hyperthyroidism, subclinical hyperthyroidism also appears to be associated with decreased bone mineral density (BMD) as reviewed by Heemstra et al. $(3,11,12)$.
An important development has been the discovery of the thyrotropin (TSH) receptor (TSHR) in bone (13-15). It has been reported that TSHR knockout and haploinsufficient mice with normal thyroid hormone levels have decreased bone mass suggesting that TSH might directly influence bone remodeling $(5,14,16)$. This is intriguing, because effects on bone metabolism that were previously ascribed to high thyroid hormone levels could also be attributed to suppressed TSH levels $(5,16,17)$. Furthermore, in animal studies, low doses of TSH increased bone volume and improved microarchitecture in ovariectomized rats (18), without increasing serum thyroid hormone levels. However, the concept has been challenged by investigations concluding that bone loss in thyrotoxicosis is mediated predominantly by thyroid hormone receptor (TR)- $\alpha$ (19). The functional role of a TSHR in bone has been studied in humans to a limited 
extent. The relationship between low TSH levels and decreased BMD has been documented in humans (20, 21), but this could still be attributed to elevated thyroid hormone levels. In a study of patients in follow-up for differentiated thyroid carcinoma (DTC), a supraphysiological dose of recombinant human TSH had thyroid hormone-independent effects on bone metabolism parameters (22). We therefore decided to study the independent relationship between serum TSH levels and indicators of bone turnover in thyroidectomized patients for differentiated thyroid carcinoma receiving thyroid hormone substitution. The advantage of this group is that these subjects have more uniform free thyroxine $\left(\mathrm{FT}_{4}\right)$ levels. As it was recently reported that the TSHRAsp727Glu polymorphism was associated with $2.3 \%$ higher BMD in elderly carriers (23), we also decided to study this relationship and BMD in these patients. Although the functional consequences of the polymorphism are debated (24), the lower plasma TSH levels in patients carrying the polymorphism could point toward a higher sensitivity of the variant compared with the wildtype TSHR $(25,26)$. We hypothesized that a group of thyroidectomized patients receiving thyroid hormone substitution would be optimal to study the relationship between the TSHR-Asp727Glu polymorphism and bone as these subjects are not expected to show compensatory lower serum TSH levels if they carry the TSHRAsp727Glu polymorphism $(25,26)$.

\section{Patients and methods}

Patients were recruited from the outpatient clinic of the Department of Endocrinology of Leiden University Medical Center. Patients were included in the study who had a diagnosis of DTC, for which they had been treated by near-total thyroidectomy, followed by routine postoperative I-131 radioiodine ablation therapy, in all but four cases. All patients were cured as defined by the absence of I-131 accumulation at diagnostic scintigraphy, serum thyroglobulin concentrations below $2 \mu \mathrm{g} / \mathrm{l}$ after TSH stimulation, the absence of Tg antibodies, a normal neck ultrasound, and no other indication for disease (27). Patients with tumor relapse were only included if they were subsequently cured.

None of the patients used any drug or had a disease known to influence bone metabolism, including estrogenreplacement therapy. Patients taking calcium or vitamin D supplements were also excluded. The Leiden University Medical Center ethics committees approved the study, and written informed consent was obtained from all subjects.

\section{Study design}

After an overnight fast, patients had a full clinical examination, including height (meters $(\mathrm{m})$ ) and weight (kilograms (kg)). Blood was collected and measured for $\mathrm{TSH}, \mathrm{FT}_{4}$, triiodothyronine $\left(\mathrm{T}_{3}\right)$, calcium, parathyroid hormone (PTH), 25-hydroxy-vitamin D (25(OH)vitD), bone-specific alkaline phosphatase (BAP), C-cross-linking terminal telopeptide of type I collagen (CTx), and procollagen type 1 aminoterminal propeptide (P1NP). Second morning void urine was measured for excretion of $\mathrm{N}$-telopeptide of collagen cross-links (NTx). We choose not to measure cathepsin $\mathrm{K}$ or TRAP levels for various reasons, including age and gender differences $(28,29)$. Furthermore, CTx seems to reflect bone resorption better than TRAP, especially during hyperthyroidism (29). Plasma, serum, and urine samples were handled immediately and stored at $-80^{\circ} \mathrm{C}$ in Sarstedt tubes. BMD (expressed in grams per square centimeter) was measured at the femoral neck and the lumbar spine (vertebrae L2-L4) by dual energy X-ray absorptiometry (NHAMES adjusted, Hologic 4500, Hologic Inc., Bedford, MA, USA). Osteopenia was defined as a T-score between -1 and -2.5 according to the WHO criteria. Osteoporosis was defined as a T-score below -2.5 according to the WHO criteria or the presence of fractures at an X-ray of the thoracic and lumbar vertebral column. As fractures of the lumbar vertebrae can affect BMD measurements by increasing X-ray resorption and therefore lead to inappropriate BMD values. We therefore excluded patients with fractures of the lumbar vertebrae from the BMD analyses. The following data were recorded: smoking habits, alcohol use, physical activity, calcium intake, medication (including self-prescription drugs) or vitamin or mineral supplements, and daily calcium intake, and for females: date of first menstruation (menarche), date of last menstruation, cycle regularity, and estrogen substitution.

\section{Serum biochemistry}

Serum $\mathrm{FT}_{4}$ and TSH were measured using a chemoluminescence immunoassay with a Modular Analytics E-170 system (intraassay CV of $1.6-2.2 \%$ and $1.3-5.0 \%$ respectively (Roche)). Serum $\mathrm{T}_{3}$ was measured with a fluorescence polarization immunoassay, $\mathrm{CV}$ values $2.5-$ $9.0 \%$, on an ImX system (Abbott). Thyroglobulin was measured by Dynotest TG-s (Brahms Diagnostica GmbH, Berlin, Germany). Plasma PTH was measured using IRMA (Nichols Diagnostic Institutes, Wijchen, The Netherlands), calcium by colorimetry, and $25(\mathrm{OH})$ vitD by RIA (Incstar/DiaSorin, Stillwater, MN, USA). Serum BAP was measured by RIA (Hybritech Europe, Liege, Belgium), CTx, and P1NP by chemoluminescence immunoassay with the Modular Analytics E-170 system (Roche Diagnostics). NTx was measured by ELISA (Ostex International Inc., Seattle, WA, USA). NTx was expressed as the ratio of urine creatinine excretion (NTx/creatinine) to correct for differences in creatinine excretion.

\section{Genotyping}

DNA was isolated from peripheral leucocytes by the salting out procedure (30). Genotypes were determined 
using 5 ng genomic DNA by a $5^{\prime}$-fluoregenic Taqman assay and reactions were performed in 384-wells format on ABI9700 $2 \times 384$ well PCR machines with endpoint reading on the ABI 7900HT TaqMan machine (Applied Biosystems, Nieuwerkerk aan den Ijssel, The Netherlands). Primer and probe sequences were optimized using the single nucleotide polymorphism assay-by-design service of Applied Biosystems.

\section{Statistical analysis}

Values are presented as mean \pm s.D., mean \pm s.E.M., median (range), or as numbers or proportions of patients. Non-normally distributed data (TSH and PTH) were directly log transformed. Factors contributing to BMD and indicators of bone turnover were first identified using univariate regression analysis. During univariate regression analysis, corrected for age, gender, and estrogen status (estrogen deplete/replete), the relationships between BMD and the following parameters were analyzed: BMI, smoking, alcohol use, physical activity, duration of follow-up after initial therapy for DTC, total dose of radioiodine received, serum levels of calcium (corrected for an albumin concentration of $42 \mathrm{~g} / \mathrm{l}$ ), 25(OH)vitD, InPTH, $\mathrm{FT}_{4}, \mathrm{~T}_{3}$, InTSH, and daily dose of thyroxine. The independent contributions of the TSHRAsp727Glu polymorphism and serum TSH levels to BMD and indicators of bone turnover were studied by entering $\mathrm{FT}_{4}, \mathrm{~T}_{3}$, age, gender, estrogen status, and all significant covariates at univariate analysis in a multivariate model. Deviation from Hardy-Weinberg equilibrium was analyzed using a $\chi^{2}$ test. All calculations were performed using SPSS 12.0 for Windows (SPSS, Inc., Chicago, IL, USA). Differences were considered statistically significant at $P<0.05$.

\section{Results}

\section{Patient characteristics}

Of a potential 330 patients with cured DTC, 105 were excluded for various reasons (Fig. 1). Sixty-nine patients did not want or were not able to participate in the study for reasons of time or geographical distance. A total of 156 patients were therefore included in the study. Eight patients were left out from analyses because of incomplete data. The basal characteristics of the 148 patients included in the study are shown in Table 1. Thirteen patients had post-surgical hypoparathyroidism for which they were adequately supplemented with active vitamin D metabolites and calcium as required. All patients were receiving L-thyroxine treatment at a mean dose of $182 \pm$ $51 \mu \mathrm{g} /$ day. The $25 \mathrm{th}, 50 \mathrm{th}$, and $75 \mathrm{th}$ percentiles of serum $\mathrm{FT}_{4}$ levels were 19.5, 22.1, and $24.9 \mathrm{pmol} / \mathrm{l}$. A total of $4.3 \%$ of the patients met the criteria of osteoporosis and $34 \%$ of the patients met the criteria for osteopenia (Table 2).

\section{Serum TSH levels, BMD, and indicators of bone turnover}

All thyroid-related parameters as well as covariates that contributed significantly to BMD and indicators of bone

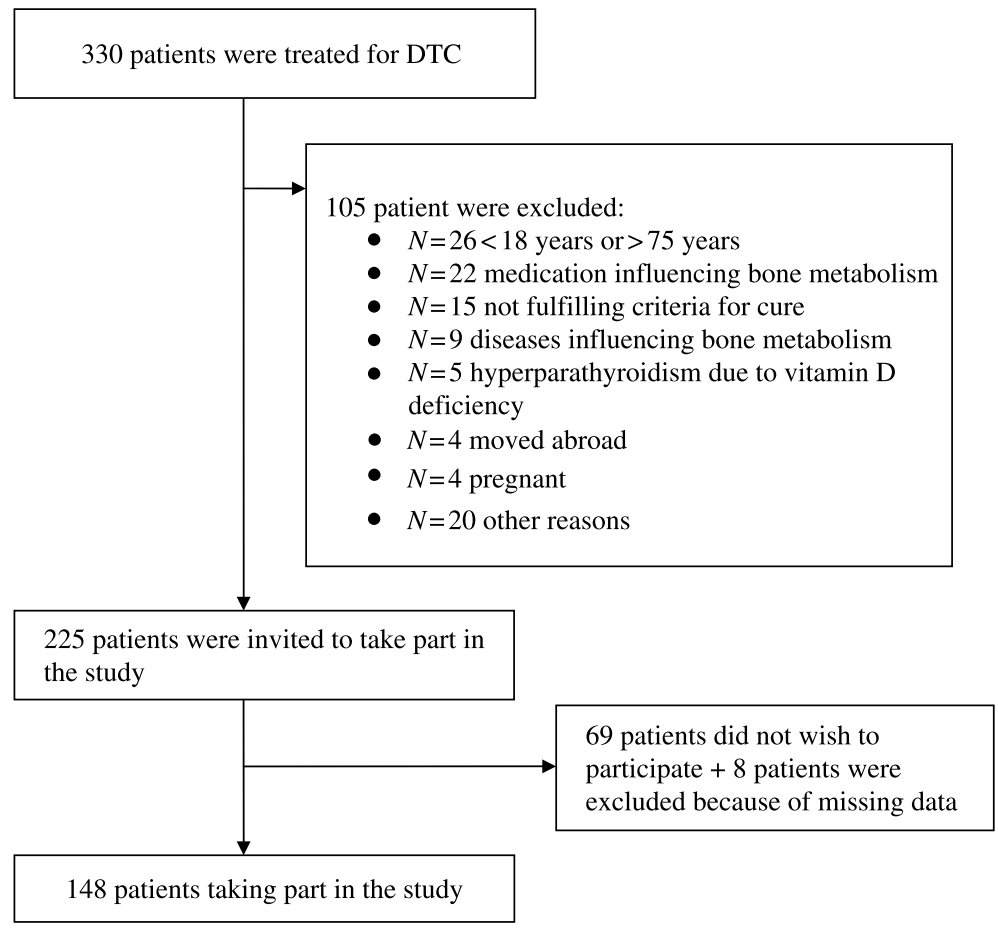

Figure 1 Study flow chart. 
Table 1 Characteristics of patients.

\begin{tabular}{ll}
\hline & Total $(n=148)$ \\
\hline Age (years) & $49.4 \pm 12.7$ \\
Males & $27(18.2 \%)$ \\
Females, premenopausal/ & $76(51.4 \%) / 45(30.4 \%)$ \\
postmenopausal & \\
Histology & \\
Papillary thyroid carcinoma & $122(82.4 \%)$ \\
Follicular thyroid carcinoma & $26(17.6 \%)$ \\
pTNM stage & \\
T1-3 N0 M0/T1-3 N1 M0/T4 or M1 & $90(60.8 \%) / 39(26.4 \%)$ \\
& $/ 19(12.8 \%)$ \\
Relapse & $18(12.2 \%)$ \\
Follow-up duration (years) & $9.3(1.2-43.0)$ \\
FT 4 (pmol/l) & $22.3 \pm 4.1$ \\
$\mathrm{~T}_{3}$ (nmol//) & $1.47 \pm 0.34$ \\
TSH (mU/l) & $0.045(0.003-6.830)$ \\
Thyroxin dose/weight $(\mu \mathrm{g} / \mathrm{kg})$ & $2.15 \pm 0.99$ \\
Age menarche women (years) & $13.3 \pm 1.4$ \\
Smoking & $18(12.2 \%)$ \\
Regular physical activity & $77(52.0 \%)$ \\
BMl (kg/m $\left.{ }^{2}\right)$ & $25.83 \pm 4.50$ \\
\hline
\end{tabular}

Data are presented as mean \pm s.D., median (range), or number of patients (percentage). $\mathrm{FT}_{4}$, free thyroxine; $\mathrm{T}_{3}$, triiodothyronine; $\mathrm{TSH}$, thyrotropin; $\mathrm{BMI}$, body mass index.

turnover are shown (Table 3). No significant association was observed between serum TSH levels, serum thyroid hormone levels, and BMD. However, using univariate analyses, the natural logarithm of serum TSH levels (and the unconverted values) appeared to be significantly inversely correlated to CTx, P1NP, BAP, and NTx (Fig. 2). The significance was sustained after correction for $\mathrm{FT}_{4}, \mathrm{~T}_{3}$, gender, age, estrogen status, and other significant determinants of bone metabolism using multivariate analysis. The relationship of serum TSH levels with indicators of bone turnover was independent from circulating thyroid hormone levels. Using multivariate analyses, no significant or relevant relationship was found between $\mathrm{FT}_{4}$ or $\mathrm{T}_{3}$ and $\mathrm{BMD}$ or indicators of bone turnover.

\section{The TSHR Asp727Glu polymorphism, BMD, and indicators of bone turnover}

Genotype frequencies of the TSHR-Asp727Glu polymorphism $($ Asp/Asp $=131 \quad(88.5 \%), \quad$ Asp/Glu $=17$ $(11.5 \%)$, and Glu/Glu $=0(0.0 \%))$ did not deviate from Hardy-Weinberg equilibrium proportions. The Glu ${ }^{727}$ allele had a frequency of $6.1 \%$, which is similar to previous studies in Caucasians (26). Patient groups were comparable with respect to age, gender, duration of follow-up, BMI, and thyroid hormone parameters. Using univariate analysis, the TSHR-Asp727Glu polymorphism appeared to be a significant determinant of BMD. After correction for age, gender, and estrogen status, carriers of the TSHR-Glu ${ }^{727}$ allele had an $8.1 \%$ higher femoral neck BMD $(P=0.023)$. When BMI was added as a covariate in the analysis of the relationship of the TSHR Asp727Glu polymorphism with femoral neck $\mathrm{BMD}$, the significance level decreased to $P=0.102$, the standardized $\beta$ decreasing from 0.172 to 0.127 (Table 3 ). There was no significant difference in BMD at the lumbar spine between groups. No significant differences were observed in indicators of bone turnover between groups (Table 2). The above-mentioned relationship between

Table 2 Bone mineral density and indicators of bone turnover.

\begin{tabular}{|c|c|c|c|c|c|}
\hline $\begin{array}{l}\text { Bone mineral } \\
\text { density }\end{array}$ & Men $(n=27)$ & $\begin{array}{l}\text { Women premeno- } \\
\text { pausal }(n=76)\end{array}$ & $\begin{array}{l}\text { Women postmeno- } \\
\text { pausal }(n=45)\end{array}$ & $\begin{array}{l}\text { Wild-type TSHR- } \\
\text { Asp727Glu }(n=131)\end{array}$ & $\begin{array}{c}\text { Heterozygous } \\
\text { TSHR-Asp727Glu } \\
(n=17)\end{array}$ \\
\hline $\begin{array}{l}\text { Femoral neck } \\
\left(\mathrm{g} / \mathrm{cm}^{2}\right)\end{array}$ & 0.90 (0.65 to 1.25$)$ & 0.88 (0.54 to 1.10$)$ & $0.79(0.56$ to 1.13$)$ & $0.86(0.54 \text { to } 1.25)^{*}$ & $0.94(0.68 \text { to } 1.25)^{*}$ \\
\hline z-score & $0.58(-1.64$ to 2.31$)$ & $0.51(-1.95$ to 2.32$)$ & $0.98(-1.67$ to 2.51$)$ & $0.55(-1.95 \text { to } 4.14)^{*}$ & $1.13(-1.18 \text { to } 3.52)^{*}$ \\
\hline $\begin{array}{l}\text { Lumbar vertebral } \\
\text { column }^{\mathrm{a}}\left(\mathrm{g} / \mathrm{cm}^{2}\right)\end{array}$ & $1.14(0.79$ to 1.37$)$ & $1.07(0.78$ to 1.31$)$ & $1.06(0.67$ to 1.37$)$ & $1.06(0.10$ to 1.74$)$ & $1.10(0.13$ to 1.34$)$ \\
\hline$z$-score & $0.84(-2.31$ to 2.64$)$ & $0.68(-2.07$ to 2.76$)$ & $0.96(-0.77$ to 2.65$)$ & $1.25(-2.31$ to 6.61$)$ & $1.38(-2.07$ to 3.38$)$ \\
\hline Osteopenia $^{\mathrm{b}}(\%)$ & 33.3 & 23 & 53.5 & 33.6 & 23.5 \\
\hline Osteoporosis ${ }^{\mathrm{b}}(\%)$ & 8.3 & 1.4 & 7 & 4.6 & 0 \\
\hline Calcium (mmol/l) & $2.36 \pm 0.02$ & $2.40 \pm 0.02$ & $2.40 \pm 0.02$ & $2.39 \pm 0.01(n=130)$ & $2.35 \pm 0.02$ \\
\hline $25(\mathrm{OH})$ vitD $(\mathrm{nmol} / \mathrm{l})$ & $66.04 \pm 4.80$ & $63.50 \pm 3.57$ & $63.5 \pm 3.57$ & $63.92 \pm 2.32$ & $65.13 \pm 6.68(n=16)$ \\
\hline $\mathrm{PTH}(\mathrm{pmol} / \mathrm{l})$ & $4.36 \pm 0.74$ & $5.15 \pm 0.46$ & $5.15 \pm 0.46$ & $5.38 \pm 0.31(n=129)$ & $3.62 \pm 0.52(n=16)$ \\
\hline $\mathrm{BAP}(\mathrm{ng} / \mathrm{ml})$ & $12.96 \pm 0.70$ & $14.30 \pm 0.78$ & $14.30 \pm 0.78$ & $\begin{array}{c}13.33 \pm 0.41 \\
(n=116)\end{array}$ & $12.05 \pm 0.64(n=14)$ \\
\hline P1NP (ng/ml) & $36.15 \pm 3.65$ & $49.88 \pm 5.27$ & $49.87 \pm 5.27$ & $\begin{array}{c}42.76 \pm 2.27 \\
\quad(n=116)\end{array}$ & $40.91 \pm 4.46(n=14)$ \\
\hline $\begin{array}{l}\text { CTx }(\mathrm{mg} / \mathrm{ml}) \\
\text { NTx/creatinine } \times \\
1 / 1000\end{array}$ & $\begin{array}{l}0.25 \pm 0.03 \\
29.96 \pm 7.22\end{array}$ & $\begin{array}{l}0.36 \pm 0.04 \\
66.44 \pm 8.61\end{array}$ & $\begin{array}{l}0.36 \pm 0.04 \\
66.44 \pm 8.61\end{array}$ & $\begin{array}{l}0.29 \pm 0.02(n=116) \\
53.71 \pm 3.86 \\
\quad(n=114)\end{array}$ & $\begin{array}{l}0.32 \pm 0.04(n=14) \\
49.86 \pm 11.13 \\
\quad(n=14)\end{array}$ \\
\hline
\end{tabular}

Data are presented as median (range), mean \pm S.E.M. or percentage. PTH, parathyroid hormone; BAP, bone-specific alkaline phosphatase; P1NP, procollagen type 1 aminoterminal propeptide; CTx, C-cross-linking terminal telopeptide of type I collagen; NTx/creatinin, ratio of urinary N-telopeptide of collagen crosslinks and creatinin concentration. *Univariate analysis, $P<0.05$ corrected for age, gender, estrogen status.

${ }^{a}$ Patients with fractures of lumbar vertebrae excluded from BMD measurements of the lumbar spine.

${ }^{\mathrm{b}}$ According to WHO criteria. 
Table 3 Association between serum TSH levels, BMD, and indicators of bone turnover.

\begin{tabular}{|c|c|c|c|c|c|c|}
\hline \multirow[b]{2}{*}{ Dependent } & \multicolumn{3}{|c|}{ Thyroid-related variables } & \multicolumn{3}{|c|}{ Co-variables } \\
\hline & Variable & Standardized $\beta$ & $P$ & Co-variable & Standardized $\beta$ & $P$ \\
\hline BMD-femoral neck & $\begin{array}{l}\mathrm{FT}_{4} \\
\mathrm{~T}_{3} \\
\text { InTSH } \\
\mathrm{TSHR}^{727} \mathrm{Glu}\end{array}$ & $\begin{array}{l}0.063 \\
-0.039 \\
0.020 \\
0.172(0.127)^{b}\end{array}$ & $\begin{array}{l}0.413 \\
0.621 \\
0.793 \\
0.023(0.102)^{b}\end{array}$ & $\mathrm{BMI}^{\mathrm{a}}$ & 0.298 & $<0.001$ \\
\hline BMD-lumbar spine & $\begin{array}{l}\mathrm{FT}_{4} \\
\mathrm{~T}_{3} \\
\text { InTSH } \\
\text { TSHR }{ }^{727} \text { Glu }\end{array}$ & $\begin{array}{r}0.038 \\
-0.014 \\
-0.026 \\
-0.028\end{array}$ & $\begin{array}{l}0.635 \\
0.867 \\
0.740 \\
0.725\end{array}$ & $\mathrm{BMI}^{\mathrm{a}}$ & 0.160 & 0.045 \\
\hline BAP & $\begin{array}{l}\mathrm{FT}_{4} \\
\mathrm{~T}_{3} \\
\text { InTSH } \\
\mathrm{TSHR}^{\mathrm{T} 27} \mathrm{Glu}\end{array}$ & $\begin{array}{l}0.148 \\
0.251(0.117)^{\mathrm{b}} \\
-0.303(-0.273)^{\mathrm{b}} \\
-0.061\end{array}$ & $\begin{array}{l}0.103 \\
0.005(0.165)^{b} \\
0.001(0.002)^{b} \\
0.509\end{array}$ & $\begin{array}{l}\mathrm{BMl} \\
\mathrm{Ca}^{\mathrm{a}} \\
\mathrm{InPTH}\end{array}$ & $\begin{array}{l}0.177 \\
0.351 \\
0.208\end{array}$ & $\begin{array}{r}0.050 \\
<0.001 \\
0.021\end{array}$ \\
\hline P1NP & $\begin{array}{l}\mathrm{FT}_{4} \\
\mathrm{~T}_{3} \\
\text { InTSH } \\
\mathrm{TSHR}^{\mathrm{a} 27} \mathrm{Glu}\end{array}$ & $\begin{array}{l}0.140 \\
0.132 \\
-0.282(-0.268)^{\mathrm{b}} \\
0.008\end{array}$ & $\begin{array}{l}0.112 \\
0.131 \\
0.001(0.002)^{b} \\
0.926\end{array}$ & $\mathrm{Ca}$ & 0.237 & 0.006 \\
\hline CTx & $\begin{array}{l}\mathrm{FT}_{4} \\
\mathrm{~T}_{3} \\
\text { InTSH } \\
\mathrm{TSHR}^{\mathrm{a} 27} \mathrm{Glu}\end{array}$ & $\begin{array}{l}0.157 \\
0.168(0.062)^{\mathrm{a}} \\
-0.302(-0.276)^{\mathrm{b}} \\
0.110\end{array}$ & $\begin{array}{l}0.078 \\
0.058(0.481)^{b} \\
0.001(0.003)^{b} \\
0.220\end{array}$ & & & \\
\hline NTx/creatinine & $\begin{array}{l}\mathrm{FT}_{4} \\
\mathrm{~T}_{3} \\
\text { InTSH } \\
\text { TSHR }^{727} \text { Glu }\end{array}$ & $\begin{array}{l}0.234(0.122)^{\mathrm{b}} \\
0.108 \\
-0.286(-0.238)^{\mathrm{b}} \\
0.021\end{array}$ & $\begin{array}{l}0.010(0.200)^{b} \\
0.240 \\
0.002(0.018)^{b} \\
0.820\end{array}$ & InPTH & 0.197 & 0.030 \\
\hline
\end{tabular}

Univariate regression analysis, all corrected for gender, age, and estrogen status. Due to a non-normal distribution, TSH and PTH were transformed by the natural logarithm. $\mathrm{FT}_{4}$, free thyroxine; $\mathrm{T}_{3}$, triiodothyronine; $\mathrm{TSH}$, thyrotropin; BMD, bone mineral density; BAP, bone-specific alkaline phosphatase; P1NP, procollagen type 1 aminoterminal propeptide; CTx, C-cross-linking terminal telopeptide of type I collagen; NTx/creatinine, ratio of urinary N-telopeptide of collagen cross-links and creatinine concentration.

${ }^{a}$ Variable with sustained significant association at multivariate analysis.

${ }^{b}$ Values obtained with a multivariate regression model in which covariables that were significant using univariate analysis were included.

TSH and parameters of bone metabolism was not influenced by the TSHR polymorphism.

\section{Discussion}

The purpose of the present study was to identify the relationship between TSH levels, BMD, and indicators of bone turnover in 148 thyroidectomized patients. In support for a potential direct effect of TSH on bone, we observed an inverse relationship between serum TSH levels and indicators of bone formation (BAP and P1NP) and bone resorption (CTx and NTx), independent of serum thyroid hormone levels. These results are consistent with a suppressive effect of TSH on bone remodeling and are in keeping with the reported effects of TSH on bone metabolism in animal studies (14). It may well be that the lower range of TSH levels in our patient group, and the more uniform $\mathrm{FT}_{4}$ concentrations (25th and 75th percentiles being 19.5 and $24.9 \mathrm{pmol} / \mathrm{l}$ ) have allowed to identify this relationship. We noticed no relationship between serum TSH levels and BMD, while we found an inverse relationship between serum TSH levels and indicators of bone turnover. This could be due to the fact that the TSH levels were measured at one occasion. BMD is acquired by a lifelong process, whereas indicators of bone turnover reflect short-term biochemical effects. Kim et al. and Morris et al. found a relationship between not only below normal TSH and BMD but also between low-normal TSH and BMD $(21,31)$. An explanation for this difference could be that Kim et al. and Morris et al. excluded patients with thyroid disease whereas we studied DTC patients. It may be objected that TSH measured at one occasion may not reflect the overall suppression of TSH over time. To address this shortcoming, we collected all TSH measurements after initial therapy of the patients who participated in the study, with the exception of stimulated TSH levels. We calculated for each patient the slope of TSH levels, to verify changes over time. An average of 15 TSH measurements per patient were obtained and we calculated a slope of TSH values of -0.0001 (range -0.004 to 0$) \mathrm{mU} / \mathrm{l}$ per year, thus indicating stable TSH levels over time.

We also hypothesized that the TSHR-Asp727Glu polymorphism, which is associated with serum TSH, but not $\mathrm{FT}_{4}$, may influence BMD and bone metabolism in humans. Although we found that carriers of the TSHR-Asp727Glu polymorphism had a higher BMD when compared with 131 non-carriers, the relationship in our study was no longer significant after correction for BMI. This may imply that the effect of the polymorphism is explained by BMI, which is also in 

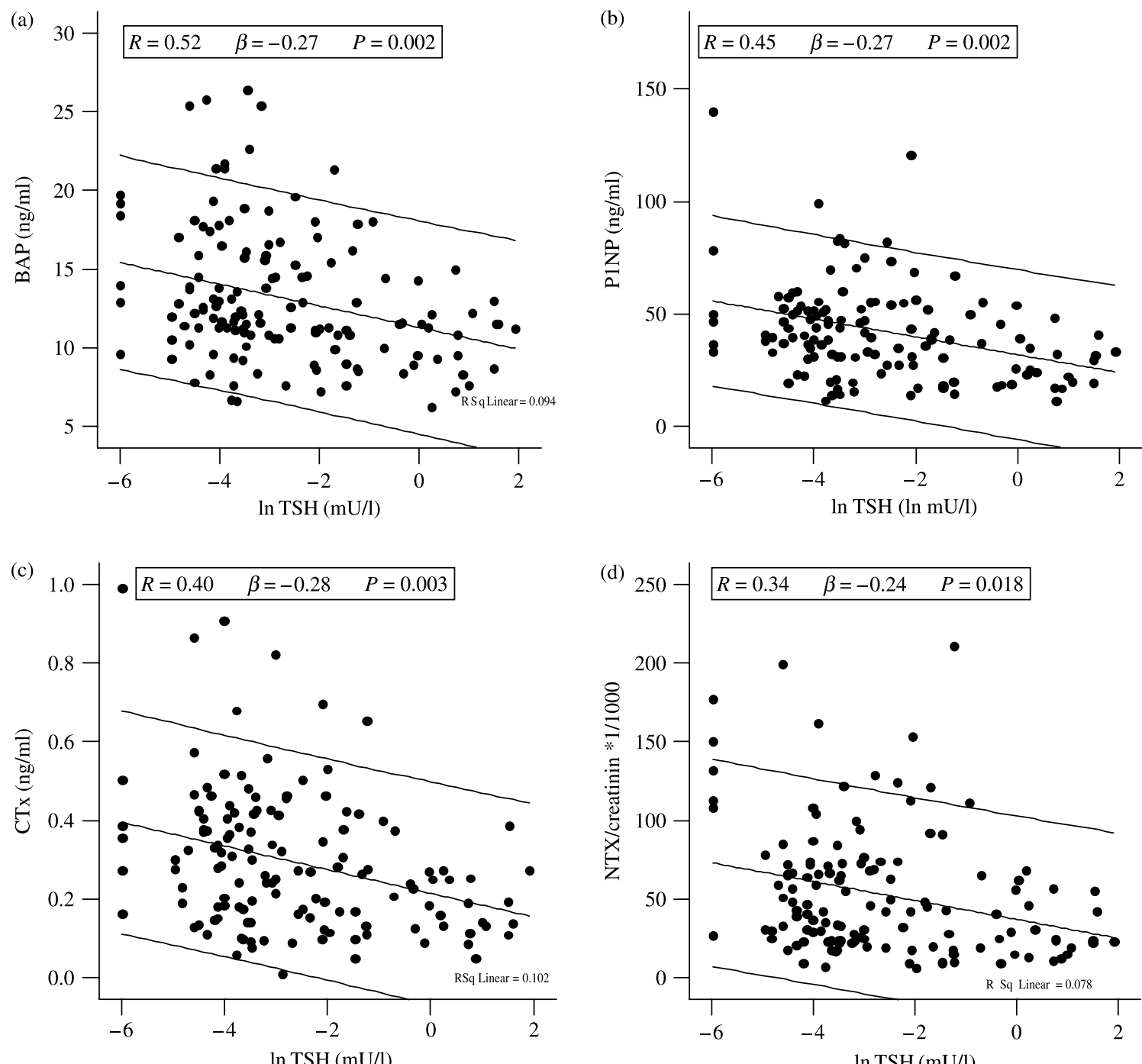

Figure 2 Relationship between the natural logarithm of serum TSH and (a) bone-specific alkaline phosphatase (BAP), (b) procollagen type 1 aminoterminal propeptide (P1NP) levels, (c) C-cross-linking terminal telopeptide of type I collagen, and (d) ratio of urinary N-telopeptide of collagen cross-links and creatinine concentration. The outer lines express the $95 \%$ confidence interval of the regression line. The middle line is the regression line. Correlations coefficients, standardized $\beta$ values and $P$ values are given for multivariate regression, including significant co-variables for parameters of bone metabolism according to Table 3.

agreement with the study of van der Deure et al. (23). An explanation for the difference in outcome of our study and the study of van der Deure et al. could be that the number of patients in our study was too small to detect a significant correlation between the polymorphism and BMD. We did not find an association of serum TSH levels with lumbar spine BMD. This might be due to the fact that the BMD measurements of the lumbar spine are influenced by osteoarthritis and therefore cannot be accurately assessed (32).

The mechanisms of TSH effects on bone metabolism have not been fully elucidated. In a provocative study, Abe et al. suggested that TSH inhibits osteoclast formation and survival by attenuating Jun N-terminal kinase $(\mathrm{JNK}) / \mathrm{c}$-jun and $\mathrm{NF \kappa B}$ signaling in response to
RANK-L and inhibits osteoblast differentiation and type 1 collagen expression as well by downregulating Wnt and vascular endothelial growth factor (VEGF) signaling (14). The same group found that TSH directly inhibits tumour necrosis factor- $\alpha$ (TNF- $\alpha$ ) production and that TNF- $\alpha$ is the critical cytokine mediating the downstream antiresorptive effects of TSH on the skeleton (33). Other authors suggested that serum TSH activates the type 2 deiodinase in osteoblasts, thereby linking TSH and increased local thyroid hormone availability (15). Our data are in agreement with the notion of a direct effect of TSH on bone, as we found a significantly inverse relationship between serum TSH levels and indicators of bone formation and degradation, which is consistent with an overall 
suppressive effect on bone turnover. However, two recent papers by Bassett et al. added to the controversy on the net contribution of TSH to BMD and bone metabolism $(19,34)$. Bassett et al. studied mice with complete or haploinsufficiency of TR- $\alpha$ and $-\beta$. They found skeletal hypothyroidism and osteosclerosis accompanied by reduced osteoclastic bone resorption in adult mice lacking TR- $\alpha$, whereas young mice had delayed endochondral ossification, in the presence of normal circulating thyroid hormone and TSH concentrations. Adult mice lacking the TR- $\beta$, leading to elevated TSH and thyroid hormone levels, had skeletal hyperthyroidism, with evidence of increased bone resorption. The authors concluded that TR- $\alpha$ regulates both skeletal development and adult bone maintenance, with euthyroid status during development being essential to establish normal adult bone structure and mineralization. In the study of van der Deure et al. (23), a stronger effect of $\mathrm{FT}_{4}$ than TSH on BMD was observed, which supports the importance of thyroid hormone effects on bone. In our study, which involved a different patient group in many respects, we did not find a relationship between serum levels of $\mathrm{FT}_{4}, \mathrm{TSH}$, and BMD, which may well be due to the fact that serum thyroid hormone and TSH levels have changed after the thyroidectomy. Indeed, despite the low serum TSH levels in most patients, overall BMD was within the normal age-corrected range, which is in line with a recent report in DTC patients (35).

It is obvious that the net contribution of TSH in bone development and bone metabolism has not been established yet. We believe that our study may add important human data to the determination of the role of TSH in bone metabolism, since we were able to study the independent relationship between serum TSH and bone in thyroidectomized patients.

In summary, we found an independent inverse relationship between serum TSH levels and biochemical indicators of bone turnover, which may point to a functional role of the TSHR in bone in humans. This study documents a direct effect of TSH, independent of thyroid hormone levels on BMD and indicators of bone turnover in humans. Further research into the mechanisms of TSH in bone metabolism needs to be performed.

\section{References}

1 Franklyn JA, Betteridge J, Daykin J, Holder R, Oates GD, Parle JV, Lilley J, Heath DA \& Sheppard MC. Long-term thyroxine treatment and bone mineral density. Lancet 1992340 9-13.

2 Greenspan SL \& Greenspan FS. The effect of thyroid hormone on skeletal integrity. Annals of Internal Medicine 1999130 750-758.

3 Heemstra KA, Hamdy NA, Romijn JA \& Smit JW. The effects of thyrotropin-suppressive therapy on bone metabolism in patients with well-differentiated thyroid carcinoma. Thyroid $2006 \mathbf{1 6}$ 583-591.

4 Murphy E \& Williams GR. The thyroid and the skeleton. Clinical Endocrinology $200461285-298$.
5 Galliford TM, Murphy E, Williams AJ, Bassett JH \& Williams GR. Effects of thyroid status on bone metabolism: a primary role for thyroid stimulating hormone or thyroid hormone? Minerva Endocrinologica $200530237-246$.

6 Eriksen EF, Mosekilde L \& Melsen F. Trabecular bone remodeling and bone balance in hyperthyroidism. Bone 19856 421-428.

7 Mosekilde L, Melsen F, Bagger JP, Myhre-Jensen O \& Schwartz SN. Bone changes in hyperthyroidism: interrelationships between bone morphometry, thyroid function and calcium-phosphorus metabolism. Acta Endocrinologica 197785 515-525.

8 Basset P, Okada A, Chenard MP, Kannan R, Stoll I, Anglard P, Bellocq JP \& Rio MC. Matrix metalloproteinases as stromal effectors of human carcinoma progression: therapeutic implications. Matrix Biology 199715 535-541.

9 Kanatani M, Sugimoto T, Sowa H, Kobayashi T, Kanzawa M \& Chihara K. Thyroid hormone stimulates osteoclast differentiation by a mechanism independent of RANKL-RANK interaction. Journal of Cellular Physiology 2004201 17-25.

10 Miura M, Tanaka K, Komatsu Y, Suda M, Yasoda A, Sakuma Y, Ozasa A \& Nakao K. A novel interaction between thyroid hormones and $1,25(\mathrm{OH})(2) \mathrm{D}(3)$ in osteoclast formation. Biochemical and Biophysical Research Communications 2002291 987-994.

11 Salerno M, Lettiero T, Esposito-del Puente A, Esposito V, Capalbo D, Carpinelli A, Padula S \& del Puente A. Effect of long-term Lthyroxine treatment on bone mineral density in young adults with congenital hypothyroidism. European Journal of Endocrinology $2004151689-694$.

12 Lee WY, Oh KW, Rhee EJ, Jung CH, Kim SW, Yun EJ, Tae HJ, Baek KH, Kang MI, Choi MG, Yoo HJ \& Park SW. Relationship between subclinical thyroid dysfunction and femoral neck bone mineral density in women. Archives of Medical Research 200637 511-516.

13 Inoue M, Tawata M, Yokomori N, Endo T \& Onaya T. Expression of thyrotropin receptor on clonal osteoblast-like rat osteosarcoma cells. Thyroid $1998 \mathbf{8} 1059-1064$.

14 Abe E, Marians RC, Yu W, Wu XB, Ando T, Li Y, Iqbal J, Eldeiry L, Rajendren G, Blair HC, Davies TF \& Zaidi M. TSH is a negative regulator of skeletal remodeling. Cell 2003115 151-162.

15 Morimura T, Tsunekawa K, Kasahara T, Seki K, Ogiwara T, Mori M \& Murakami M. Expression of type 2 iodothyronine deiodinase in human osteoblast is stimulated by thyrotropin. Endocrinology 2005146 2077-2084.

16 Sun L, Davies TF, Blair HC, Abe E \& Zaidi M. TSH and bone loss. Annals of the New York Academy of Sciences 20061068 309-318.

17 Davies T, Marians R \& Latif R. The TSH receptor reveals itself. Journal of Clinical Investigation 2002110 161-164.

18 Sampath TK, Simic P, Sendak R, Draca N, Bowe AE, O'Brien S, Schiavi SC, McPherson JM \& Vukicevic S. Thyroid-stimulating hormone restores bone volume, microarchitecture, and strength in aged ovariectomized rats. Journal of Bone and Mineral Research 200722 849-859.

19 Bassett JH, O'Shea PJ, Sriskantharajah S, Rabier B, Boyde A, Howell PG, Weiss RE, Roux JP, Malaval L, Clement-Lacroix P, Samarut J, Chassande O \& Williams GR. Thyroid hormone excess rather than thyrotropin deficiency induces osteoporosis in hyperthyroidism. Molecular Endocrinology 200721 1095-1107.

20 Bauer DC, Ettinger B, Nevitt MC \& Stone KL. Risk for fracture in women with low serum levels of thyroid-stimulating hormone. Annals of Internal Medicine 2001134 561-568.

21 Kim DJ, Khang YH, Koh JM, Shong YK \& Kim GS. Low normal TSH levels are associated with low bone mineral density in healthy postmenopausal women. Clinical Endocrinology 200664 86-90.

22 Mazziotti G, Sorvillo F, Piscopo M, Cioffi M, Pilla P, Biondi B, Iorio S, Giustina A, Amato G \& Carella C. Recombinant human TSH modulates in vivo C-telopeptides of type- 1 collagen and bone alkaline phosphatase, but not osteoprotegerin production in postmenopausal women monitored for differentiated thyroid carcinoma. Journal of Bone and Mineral Research 200520 $480-486$. 
23 van der Deure WM, Uitterlinden AG, Hofman A, Rivadeneira F, Pols HA, Peeters RP \& Visser TJ. Effects of serum TSH and FT4 levels and the TSHR-Asp727Glu polymorphism on bone: the Rotterdam Study. Clinical Endocrinology 200868 175-181.

24 Haraguchi K, Saito T, Kaneshige M, Endo T \& Onaya T. Desensitization and internalization of a thyrotrophin receptor lacking the cytoplasmic carboxy-terminal region. Journal of Molecular Endocrinology 199413 283-288.

25 Peeters RP, van TH, Klootwijk W, de Rijke YB, Kuiper GG, Uitterlinden AG \& Visser TJ. Polymorphisms in thyroid hormone pathway genes are associated with plasma TSH and iodothyronine levels in healthy subjects. Journal of Clinical Endocrinology and Metabolism $2003 \mathbf{8 8} 2880-2888$.

26 Hansen PS, van der Deure WM, Peeters RP, Iachine I, Fenger M, Sorensen TI, Kyvik KO, Visser TJ \& Hegedus L. The impact of a TSH receptor gene polymorphism on thyroid-related phenotypes in a healthy Danish twin population. Clinical Endocrinology 200766 827-832.

27 Cooper DS, Doherty GM, Haugen BR, Kloos RT, Lee SL, Mandel SJ, Mazzaferri EL, McIver B, Sherman SI \& Tuttle RM. Management guidelines for patients with thyroid nodules and differentiated thyroid cancer. Thyroid $2006 \mathbf{1 6} 109-142$.

28 Kerschan-Schindl K, Hawa G, Kudlacek S, Woloszczuk W \& Pietschmann P. Serum levels of cathepsin K decrease with age in both women and men. Experimental Gerontology 2005 $40532-535$.

29 Minisola S, Dionisi S, Pacitti MT, Paglia F, Carnevale V, Scillitani A, Mazzaferro S, De GS, Pepe J, Derasmo E \& Romagnoli E. Gender differences in serum markers of bone resorption in healthy subjects and patients with disorders affecting bone. Osteoporosis International 200213 171-175.
30 Miller SA, Dykes DD \& Polesky HF. A simple salting out procedure for extracting DNA from human nucleated cells. Nucleic Acids Research $1988 \mathbf{1 6} 1215$.

31 Morris MS. The association between serum thyroid-stimulating hormone in its reference range and bone status in postmenopausal American women. Bone $2007 \mathbf{4 0} 1128-1134$.

32 Burger $H$, van Daele PL, Algra D, van den Ouweland FA, Grobbee DE, Hofman A, van Kuijk C, Schutte HE, Birkenhager JC \& Pols HA. The association between age and bone mineral density in men and women aged 55 years and over: the Rotterdam Study. Bone and Mineral 199425 1-13.

33 Hase H, Ando T, Eldeiry L, Brebene A, Peng Y, Liu L, Amano H, Davies TF, Sun L, Zaidi M \& Abe E. TNFalpha mediates the skeletal effects of thyroid-stimulating hormone. PNAS $2006 \mathbf{1 0 3}$ 12849-12854.

34 Bassett JH, Nordstrom K, Boyde A, Howell PG, Kelly S, Vennstrom B \& Williams GR. Thyroid status during skeletal development determines adult bone structure and mineralization. Molecular Endocrinology 200721 1893-1904.

35 Reverter JL, Holgado S, Alonso N, Salinas I, Granada ML \& Sanmarti A. Lack of deleterious effect on bone mineral density of long-term thyroxine suppressive therapy for differentiated thyroid carcinoma. Endocrine-Related Cancer 200512 973-981.

Received 2 April 2008

Accepted 2 April 2008 